\title{
Accountability: a missing construct in models of adherence behavior and in clinical practice
}

This article was published in the following Dove Press journal:

Patient Preference and Adherence

25 July 2017

Number of times this article has been viewed

\author{
Elias Oussedik' \\ Capri G Foy ${ }^{2}$ \\ E J Masicampo 3 \\ Lara K Kammrath ${ }^{3}$ \\ Robert E Anderson' \\ Steven R Feldman ${ }^{1,4,5}$ \\ 'Center for Dermatology Research, \\ Department of Dermatology, Wake \\ Forest School of Medicine, Winston- \\ Salem, NC, USA; ${ }^{2}$ Department \\ of Social Sciences and Health \\ Policy, Wake Forest School of \\ Medicine, Winston-Salem, NC, USA; \\ ${ }^{3}$ Department of Psychology, Wake \\ Forest University, Winston-Salem, NC, \\ USA; ${ }^{4}$ Department of Pathology, Wake \\ Forest School of Medicine, Winston- \\ Salem, NC, USA; ${ }^{5}$ Department of \\ Public Health Sciences, Wake Forest \\ School of Medicine, Winston-Salem, \\ NC, USA
}

\begin{abstract}
Piano lessons, weekly laboratory meetings, and visits to health care providers have in common an accountability that encourages people to follow a specified course of action. The accountability inherent in the social interaction between a patient and a health care provider affects patients' motivation to adhere to treatment. Nevertheless, accountability is a concept not found in adherence models, and is rarely employed in typical medical practice, where patients may be prescribed a treatment and not seen again until a return appointment 8-12 weeks later. The purpose of this paper is to describe the concept of accountability and to incorporate accountability into an existing adherence model framework. Based on the Self-Determination Theory, accountability can be considered in a spectrum from a paternalistic use of duress to comply with instructions (controlled accountability) to patients' autonomous internal desire to please a respected health care provider (autonomous accountability), the latter expected to best enhance long-term adherence behavior. Existing adherence models were reviewed with a panel of experts, and an accountability construct was incorporated into a modified version of Bandura's Social Cognitive Theory. Defining accountability and incorporating it into an adherence model will facilitate the development of measures of accountability as well as the testing and refinement of adherence interventions that make use of this critical determinant of human behavior.
\end{abstract}

Keywords: autonomous accountability, controlled accountability, duress, health promotion, Self-Determination Theory, shame, Social Cognitive Theory, volition

\section{Introduction}

Accountability is a tool used frequently in many settings to encourage people to follow a particular course of action. ${ }^{1}$ It is widely used to encourage human behaviors, from formal accounting of sales in business, to reporting of research progress at weekly laboratory meetings. ${ }^{2}$ The importance of accountability is illustrated by the example of piano lessons. Students take once-a-week piano lessons and have a recital in 10-12 weeks. In anticipation of each weekly lesson, students practice. If it were not for weekly piano lessons, it is unlikely that students would practice much until just before their recital. The anticipation of the weekly social interactions between the student and the teacher is critically important in holding the student accountable to practice (even if there is no formal accounting of exactly when the student practiced).

We define accountability as "the expectation of account-giving"; ${ }^{3}$ where accountability involves an expected social interaction. Accountability is not widely used to encourage adherence behavior in clinical practice. ${ }^{4,5}$ On the contrary, patients are often prescribed a medication with no follow-up until another office visit 8-12 weeks later. Accountability is far more commonly present in clinical trials (Figure 1). ${ }^{6,7}$ Clinical trials include frequent follow-up, often with review of a (not necessarily
Correspondence: Steven R Feldman Forest School of Medicine, Medical Center Boulevard, Winston-Salem, NC 27I57-I07I, USA

Tel + I 3367167740

Fax + I 3367167732

Email sfeldman@wakehealth.edu 


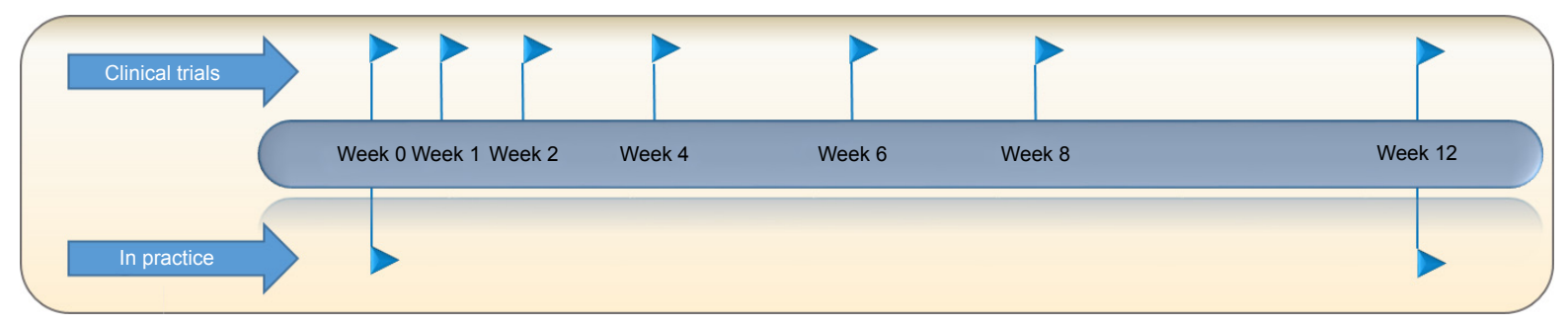

Figure I The frequency of office visits in clinical trials greatly differs compared to those seen in practice.

Notes: Clinical trials typically include assessment visits often during a study. Having a visit at baseline (week 0) and weeks I, 2, 4, 6, 8, and I 2 is common. This allows the clinical researcher to report the course and effectiveness of the intervention. In the "real world", visits typically occur every 12 weeks. The increase in office visits seen in clinical trials might indirectly increase patient adherence to the intervention. This practice lies in parallel to the flossing before the dentist and weekly piano lesson behaviors.

accurate) patient diary that recorded subjects' use of medication. The anticipation of the follow-up visit motivates research subjects to follow the clinical protocol. ${ }^{8}$ Typical clinical practice does not include frequent interval follow-up visits, and adherence is much worse in clinical practice than in clinical trials. ${ }^{9}$

The lack of accountability in clinical practice may relate to an assumption that since patients want to get well, they will take their medication without the need for external accountability. Formal models of health behavior do not make such assumptions. Health behavior theories are used to better understand why patients do not follow recommendations of health professionals and to guide development and refinement of effective adherence interventions. ${ }^{10-12}$ Interventions that use health behavior theories and specifically those that incorporate multiple theoretical concepts are more effective than those that do not. ${ }^{13-15}$

The Health Belief Model (HBM) is the oldest and most commonly used of all health behavior models. ${ }^{16}$ It views health behavior as a dynamic interaction between the possible barriers and benefits to engaging in a behavior. ${ }^{17}$ A limitation of the HBM is its lack of incorporation of social influences and social norms. ${ }^{18,19}$ Social influences, social norms, and the anticipation of a social interaction are all critical components of accountability. Many theories have tried to explain poor adherence behavior and many interventions have been developed to improve adherence, but accountability, used to foster a specified course of action throughout other spheres of human activity, has not been given strong consideration either in adherence models or in clinical practice. The purpose of this paper is to describe the concept of accountability and to incorporate accountability into an adherence model that can be used to guide development and refinement of novel adherence interventions.

\section{Accountability}

Accountability requires the expectation of being held to account. A common example of accountability is the
Hawthorne effect, that measuring a behavior changes the behavior. $^{20}$ The Hawthorne effect is embodied in the phenomenon of white coat compliance, an increase in adherence behavior observed in association with visits to a health care provider. ${ }^{21}$ Hawthorne effects, like white coat compliance, are generally considered a bias that should be avoided in research settings. ${ }^{20}$ The idea that such Hawthorne effects should be harnessed and used as a means to improve adherence has not been widely considered.

While accountability is a social phenomenon, it does not necessarily require direct human contact. Accountability partners help people keep a commitment, without the requirement of physical contact. ${ }^{22}$ The interaction can be effected through cyberspace, such as by text or instant messaging. ${ }^{23}$ The lack of requirement for direct human contact means that accountability-based adherence interventions could be implemented at low cost. An Internet-based, weekly reporting intervention increased adherence to acne treatment in adolescents by $>100 \%$ (Figure 2) ${ }^{24,25}$ A similar intervention

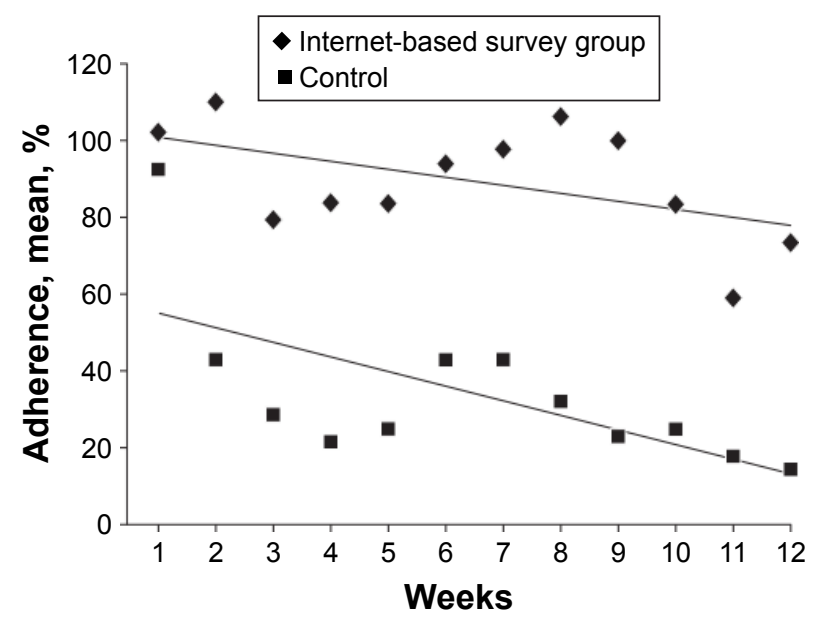

Figure 2 The effect of accountability in medication adherence.

Notes: The group randomized to the Internet-based survey (accountability intervention) once a week had higher rates of adherence over the 12-week study period. Reproduced with permission from JAMA Dermatology. 201 I; 147(I0): 1223. Copyright (C) 20II American Medical Association. All rights reserved. Yentzer BA, Wood AA, Sagransky MJ, et al. An Internet-based survey and improvement of acne treatment outcomes. ${ }^{24}$ 
was tested in adults with psoriasis and again led to increased adherence rates. ${ }^{26}$ The weekly reporting was hypothesized to instill a sense of accountability, similar to the Hawthorne effect or (cyber) "white coat compliance", ${ }^{20}$ While other electronic-based reporting interventions exist - physician chat lines, interactive programs, monitoring programs, and online surveys - none of these interventions have traditionally considered having accountability as a foundational psychobehavioral construct. ${ }^{27}$

In the acne and psoriasis Internet-based interventions, in contrast to a weekly reminder to take medication, patients were asked to report their medication experience on a weekly basis; accountability is a construct distinct from cues of action used in the HBM. ${ }^{17}$ However, whether the effectiveness of these accountability/reporting interventions was driven by fear of shame or by more positive volitional aspects has not been investigated. People adhere better when they are held accountable, particularly when they are held accountable to people they respect and who care about them. ${ }^{28}$

Furthermore, the effect of accountability was tested by Rogers during the 2010 US Senate election. By sending out a pamphlet to potential voters stating "You may receive a phone call after the election to discuss your voting experience", voting increased by $\sim 50 \% .^{29}$ Rogers suggested this behavior was driven by reputational concern. Reputational concern is driven by social interactions; it may have both negative (shame) and positive (pride) components. The soft "may" used by Rogers may have the advantage of helping to minimize oppositional defiant behavior. Rogers' findings indicate that even the expectation of the possibility of an accounting to an unconnected individual can have large effects on human behavior. ${ }^{29}$

The accountability inherent in the expectation of a social interaction between a patient and health care provider at a follow-up visit affects patients' motivation to adhere to treatment. Based on the Self-Determination Theory, we consider two extreme forms of accountability that exist in a spectrum: first, an accountability that is based on a paternalistic sense of duress that we term controlled accountability; and second, an autonomous internal desire to please that we term autonomous accountability. Based on the Self-Determination Theory, we anticipate that adherence interventions based on autonomous accountability will have the greatest long-term effectiveness.

Accountability is a new theoretical construct to adherence research. We first discuss several well-established theories of adherence behavior and how the constructs of autonomous and controlled accountability may fit within their frameworks. Then, we will discuss potential applications of this construct to facilitate adherence to health-promoting interventions, along with possible strengths and weaknesses.

\section{Existing models of health behavior}

Many health behavior models have been used to describe adherence behaviors. Health behavior theories have traditionally been characterized into three levels: an individual level, an interpersonal level, and a community level. ${ }^{16,30}$ All three of these levels allow for the identification of differing potential points of intervention. To characterize whether accountability or aspects of accountability exist in health behavior models, a review of English-language articles was performed using MEDLINE, PsycINFO, and Google Scholar using the keywords "health behavior (behaviour) models," "health intervention models," "adherence," "compliance," and "accountability" from start date to August 2016. Criteria of inclusion encompassed theories including either one of the following constructs or concepts: 1) self-efficacy; 2) motivation; 3) social support; or 4) accountability. As no health behavior theories dealing with accountability were found, a second literature search was undertaken to further characterize whether one of the well-studied health behavior theories could include aspects of accountability. Criteria of inclusion encompassed health behavior theories published in English books or those included in a meta-analysis in peer-reviewed journals. Health behavior theories belonging to a community level were excluded. The aforementioned databases were searched again using the names of the health behavior models as search terms. In November 2016, a second review of English-language articles was performed using Business Source Premier from start date to November 2016 using the keywords "accountability" and "behavior (behaviour) models" to further characterize whether formal behavior theories incorporating accountability existed in the business world and whether an accountability scale existed.

A total of eight health behavior theories met the review inclusion and exclusion criteria (Table S1). ${ }^{17,28,31-35}$ Specific focus on accountability was not found in any of these models; however, to address which of these health behavior models would lend itself well to accountability, a panel of reviewers with expertise in medicine, management, psychology, social science, and health services research were assembled between August 2016 and December 2016 for a total of five meetings.

The panel of reviewers' end focus was predicated on the Social Cognitive Theory and Self-Determination Theory, two theories that could easily incorporate aspects of accountability in health care settings. A short review of these models and how the construct of accountability may fit within their framework follows. 


\section{Self-Determination Theory}

Self-Determination Theory originates from two theories: Cognitive Evaluation Theory and Organismic Integration Theory. ${ }^{36,37}$ Cognitive Evaluation Theory purports that individuals have three basic psychological needs: competence, autonomy, and relatedness. ${ }^{38,39}$ Social interactions, a critical aspect of accountability, are also critical to the satisfaction of competence, autonomy, and relatedness ${ }^{40}$ Relatedness relates to the feeling of being cared for and having the impression of being connected to others. Competence is the feeling of mastery; where this sense of competence is portrayed by the environment - by how others react to your work. Finally, autonomy is a self-endorsing type of belief where the individual wholeheartedly believes that what he or she is doing abides to his or her core beliefs. ${ }^{28}$ All three of these psychological needs could potentially function as regulators in accountability. Individuals undertake responsibilities and execute them when they are held accountable to people they respect and to people to whom they are connected. ${ }^{28}$

Organismic Integration Theory is the second integral portion of the Self-Determination Theory. ${ }^{41}$ It broadly classifies motivation into a continuum of two broad categories: controlled and autonomous. ${ }^{42}$ Controlled motivation relies on the avoidance of shame or guilt. ${ }^{43}$ However, it has classically been portrayed as a poor parameter for motivating long-term behavior change. ${ }^{44}$ In contrast, autonomous motivation's reward is purely internal (eg, general pleasure). ${ }^{28}$ The "expectation of account-giving" through a social interaction potentially can induce both types of emotional states - one of duress, the other of volition - or some combination of the two.

\section{Social Cognitive Theory}

Bandura's Social Cognitive Theory encompasses three broad, dynamic components: personal factors, environmental factors, and behavioral factors. ${ }^{34}$ Environmental factors consider social norms, social interactions, and social support, all factors that can be considered in addressing accountability. Personal factors account for cognitive abilities, beliefs, and attitudes, while behavioral factors are mediated through selfefficacy and self-regulation. ${ }^{34}$ Personal beliefs and attitudes can modulate whether an individual portrays a potential social interaction as a form of stress, fear or shame, or as a pleasant, beneficial encounter.

Self-regulation alongside self-observation are core values in the Social Cognitive Theory. Self-observation is the first step, where the individual observes his or her behavior and thereafter uses self-regulation to control his or her response to the behavior. ${ }^{45}$ Accountability can be incorporated into such a theory through self-observation, where the individual realizes he or she is being held accountable to adhere to a certain intervention. Through accountability, patients may feel a sense of responsibility and fulfillment when satisfying their goals through self-regulation. ${ }^{34}$

Perhaps, the most well-known component of the Social Cognitive Theory is self-efficacy, or a person's belief about his or her personal ability to execute a desired behavior in a specific situation to produce an outcome. ${ }^{34,46}$ Sources of information that enhance self-efficacy include direct experience or mastery experiences, vicarious experience or modeling, verbal or social persuasion, and interpretation of physiological states. Such social norms, social interactions, and social support are all critical and underappreciated constructs that greatly help the individual engage in a behavior..$^{30}$ These experts provide a nest for social interaction and support. ${ }^{34}$ However, experts, such as health care providers, clinicians, or piano teachers, may also be prone to share aspects of accountability. In anticipation of a pupil or patient's upcoming visit, the expert may feel motivated by autonomous and controlled accountability constructs to aid the individual in engaging in a behavior. While social interactions and social support are paramount to a patient-centered accountability approach, a provider-centered accountability approach may also play a role in mediating such measures. The essence of this theory lies with reciprocal determinism; that there is a continuous, dynamic interaction between the individual, the environment, and behavior. ${ }^{30}$ It is plausible that accountability can fit within the Social Cognitive Theory by being incorporated to enhance self-awareness, self-regulation, and self-efficacy.

The main criticism of the Social Cognitive Theory lies in its broadness ${ }^{47}$ Incorporating all its constructs can be difficult and is most often only partially used. ${ }^{47}$ In a systematic review exploring the Social Cognitive Theory in chronic health condition interventions, only $52 \%$ of the interventions considered self-regulation, an important concept in Social Cognitive Theory ${ }^{47}$ However, when the model is correctly used, the results have been impressive and the theory has amassed an important research record. ${ }^{48-50}$ Another weakness of the model purports that motivation and emotion are often ignored. However, accountability has a close relation to motivation; adding accountability to the Social Cognitive Theory could eliminate one of its core weaknesses.

\section{Discussion}

A specific focus on accountability was not found in any of the identified published health behavior models. The panel of expert reviewers proposed that the Social Cognitive Theory, 
informed by the Self-Determination Theory, would be a suitable model into which accountability could be incorporated. Revisiting accountability, we stress that the "act of accounting" is not what affects adherence behavior; the expectation of account-giving through social interactions is the critical intervention, changing patients' behaviors in the days leading up to the expected social encounter. Without a social presence, the "act of accounting" is not generally plausible. While individuals may be able to account to themselves, we stress the importance of a social interaction. Accountability is generally considered an inherently extrinsic factor that, within the context of the Self-Determination Theory, may be perceived along the continuum of controlled versus autonomous motivation.

Controlled accountability is the expectation of accountgiving causing a sense of pressure or duress. An example of this is the accountability to a cold, strict piano teacher who shames students who do not practice. In this example, there is a controlling external motive for the student to practice. While the piano teacher may not have any formal, validated means for assessing how often or how much the student practiced, the student may still feel pressured to practice by the expectation of the social interaction that will take place at the lesson. In its traditional sense, accountability has mainly been considered a controlling behavior.

In contrast to controlled accountability, in autonomous accountability, a relatively novel term, the expectation of account-giving causes a behavioral change for positive reasons. Given the self-driven nature of autonomously motivated behavior, ${ }^{17}$ one would assume that an accountability figure would not be necessary for autonomous goals. However, past work suggests that autonomous behaviors do indeed benefit from an accountability figure. ${ }^{9,51}$ In the context of piano playing, an autonomously motivated learner may be excited about sharing their progress with a beloved teacher, may feel an internal sense of pride for performing well for the teacher, or may have the belief that practicing in anticipation of a lesson is simply the correct thing to do. Here, the behavior is not controlled by shame but is rather a positive self-choice, one that fits well with patient-centered medical care (Figure 3). Autonomous accountability is not purely an intrinsic motivation (in which the behavior is performed out of the enjoyment of performing the behavior); accountability to a health care professional is inherently extrinsic, although not necessarily in any way punitive. However, there are limitations to autonomous accountability, notably in sectors where the patient has not chosen to seek care but is being provided with it compulsorily. Such examples can often be prevalent

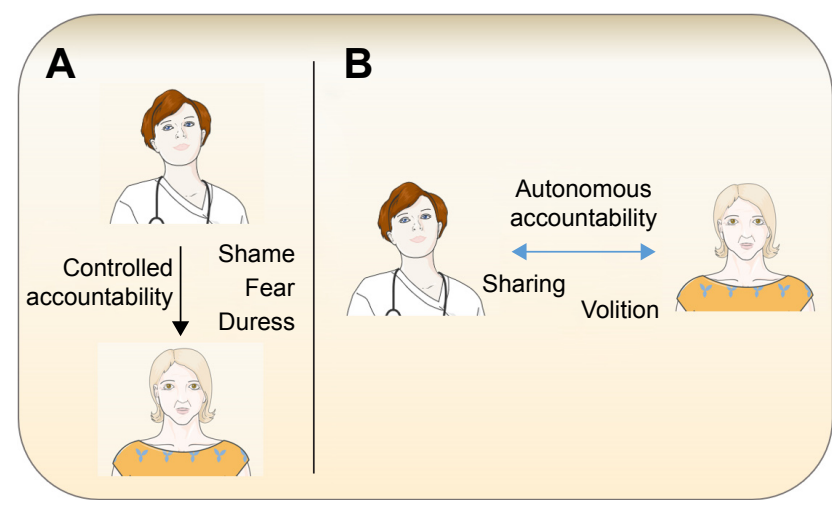

Figure 3 Autonomous accountability versus controlled accountability in clinical practice.

Notes: (A) A provider (top)/patient (bottom) interaction; one in which the health care provider makes demands and any accountability might drive fear or shame (controlled accountability). (B) A shared partnership model in which accountability to good adherence gives the patient the opportunity to please himself or herself and the provider (autonomous accountability). Adapted from Servier medical art [homepage on the Internet]. Powerpoint image bank. Servier; 2013 [modified August 8, 2013]. Available from: http://www.servier.com/Powerpoint-image-bank. ${ }^{72}$

in the mental health sector. ${ }^{52,53}$ Different environments and different populations may respond more favorably to either autonomous or controlled accountability interventions.

Within this model, shared decision-making and patient autonomy are not ignored, and on the contrary, are encouraged. Self-Determination Theory and Cognitive Evaluation Theory purport the importance of competence, autonomy, and relatedness, ${ }^{28,54}$ into which autonomous and controlled accountability fit. However, autonomous accountability shares much more of these volitional aspects than controlled accountability. Better use of an accountability figure, particularly a caring health care provider, can contribute to cognitivebehavioral interventions to improve adherence and does not need to replace patient autonomy nor shared decision-making.

While no validated accountability measurements exist in health-promotion research, the paradigm proposed here lays a foundation for creating such a measure. The availability of such a tool would permit assessments on how accountability interacts with adherence and with other validated measures. ${ }^{55-58}$ Having the tools to measure both controlled and autonomous accountability is critical as targeting selective interventions that focus more heavily on autonomous accountability may be imperative to long-term behavior change. The relationship of accountability to other constructs (Figure 4) can be assessed with preexisting, validated scales. Self-efficacy, which is expected to be modulated by accountability, can be measured through well-known and validated self-efficacy scales. The General Self-Efficacy $\mathrm{Scale}^{55}$ is a possible tool, albeit there are concerns that "all-purpose" scales that measure self-efficacy are limited in validity. ${ }^{56}$ 


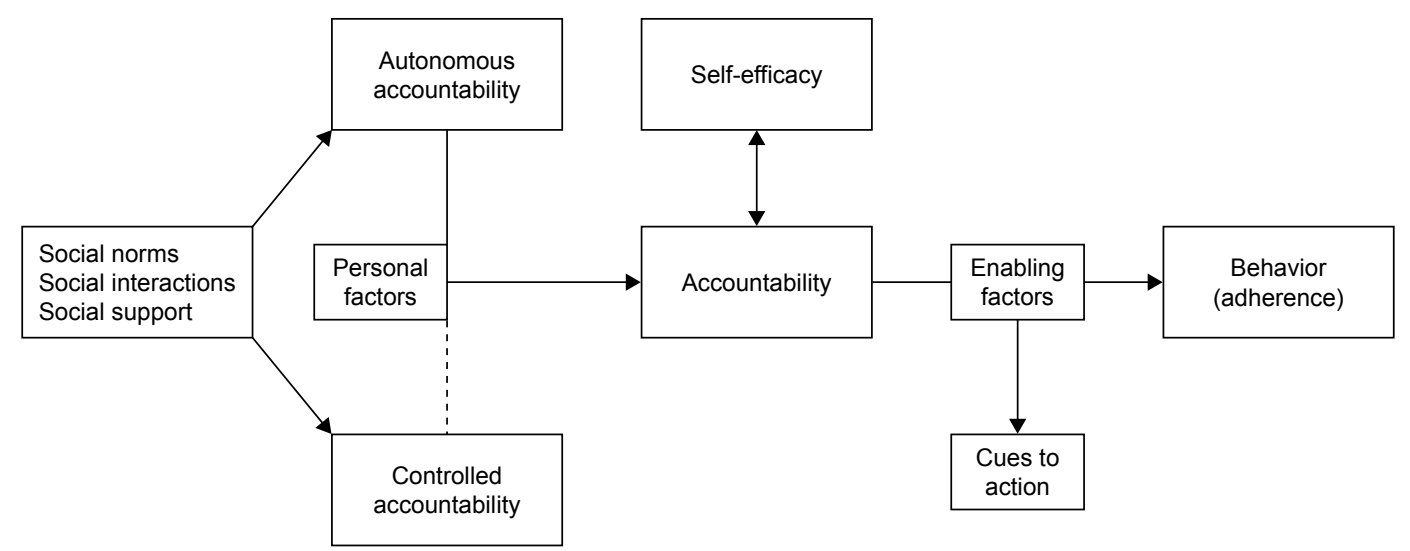

Figure 4 The inclusion of autonomous and controlled accountability in a modified version of Bandura's Social Cognitive Theory.

Notes: Autonomous and controlled accountability are regulated by social interactions. The possibility of needing to account for one's actions through a social interaction functions as a behavioral amplifier. Whether the intervention is considered a form of controlled or autonomous accountability is mediated by the individual's personal factors (knowledge, expectation, attitudes). The dashed line in the figure justifies controlled accountability as possibly having minimal impact on long-term behavioral change. Once the individual internalizes his or her sense of accountability, self-efficacy may further aid in increasing adherence. With all these different factors assimilated, enabling factors (eg, cues to action) are included as features that could potentially augment accountability and further increase adherence rates.

The relationship between accountability and social support may be measured using the Social Provisions Scale, ${ }^{57}$ while personal factors may be measured using validated national demographic surveys or other scales pertinent to the intervention, such as the Hamilton Depression Rating Scale. ${ }^{58}$ As validated accountability measurements are sought, other critical biopsychosocial correlating variables may be delineated, such as patient-provider satisfaction, ${ }^{59}$ patient-provider trust, ${ }^{60,61}$ and certain emotional states, and/or additional constructs.

The development of a validated accountability scale would allow for the design of studies permitting the formation of multiple testable hypotheses (Table 1). Such adherence studies can be designed through traditional adherencemeasuring randomized controlled trials. ${ }^{62}$ Primary outcomes

Table I Testable accountability hypotheses

\begin{tabular}{ll}
\hline Testable hypotheses & Interventional construct \\
\hline $\begin{array}{l}\text { Levels of accountability differ from } \\
\text { patient-physician, patient-nurse, }\end{array}$ & $\begin{array}{l}\text { Accountability and social } \\
\text { patient-psychologist, or other patient- } \\
\text { provider interactions } \\
\text { Gender, age, and ethnicity affect the }\end{array}$ \\
$\begin{array}{l}\text { degree of accountability between patient } \\
\text { and provider and thus affects adherence }\end{array}$ & factors \\
$\begin{array}{l}\text { Certain types of social interactions } \\
\text { between patient and provider carry } \\
\text { more weight in increasing accountability }\end{array}$ & Accountability and social \\
$\begin{array}{l}\text { and adherence } \\
\text { Autonomous accountability leads to }\end{array}$ & Autonomous and \\
$\begin{array}{l}\text { better long-term behavioral change } \\
\text { compared to controlled accountability }\end{array}$ & controlled accountability \\
\hline
\end{tabular}

Note: Multiple testable hypotheses are suggested to further refine and understand autonomous and controlled accountability. would measure adherence objectively, ${ }^{63}$ while secondary analyses would measure the psychosocial constructs in Figure 4 that mediate our theory-driven, cognitive-behavioral model, thus allowing for the objective assessment of the progress of accountability on measures of behavior or adherence. In addition, correlations between each construct and accountability (autonomous and controlled) would provide answers to the testable hypotheses (Table 1).

\section{Summary and conclusion}

Adherence in medicine is poor. ${ }^{64-67}$ Unlike the interactions in many disciplines outside of medicine, there is often a lack of accountability in provider-patient relationships. Given the lack of accountability in health care, poor adherence should not be startling. The relative lack of effectiveness of adherence interventions should not be surprising either, as such interventions - education, motivational interviewing, reminders, etc. - might be expected not to work for piano practice or other human activities in the absence of accountability.

Existing health behavior models have largely missed consideration of the importance of accountability - a clearly effective intervention. ${ }^{4,24,26,68}$ The Hawthorne effect is considered an important factor to avoid in studies of interventions. ${ }^{20}$ Health behavior models that include accountability would recognize that the Hawthorne effect is a manifestation of a powerful, valuable tool that health care providers can use to promote better adherence to treatment. Yet, existing models, notably the Social Cognitive Theory, can easily incorporate accountability and recognize the importance of social factors that drive human behavior. Self-Determination Theory, for 
example, predicts that accountability can have positive and negative components. We would anticipate that the positive components may be of greater value in promoting long-term health behavior changes.

Using the Social Cognitive Theory as a backbone model leads to the same limitations. The Social Cognitive Theory is broad and incorporating all constructs can be difficult. ${ }^{47}$ However, when all constructs are used, the predictive power of the Social Cognitive Theory is quite high. ${ }^{48}$ Although a few questions persist regarding this novel theoretical framework, this allows for the formation of testable hypotheses to fully elucidate autonomous and controlled accountability's components (Table 1). While this model is attributable to studying, and measuring adherence, measurements of the individualized constructs are important in order to better understand and target different interventions. ${ }^{69,70}$ Research studies that measure accountability - both controlled and autonomous - can help better define how accountability can best be achieved and how it can be best used to change patients' behaviors. Research issues to consider include how accountability can affect short-term changes in initial use of treatment, how initial better adherence may affect longer term use, and how accountability might be used over longer periods of time without inducing fatigue.

Humans are social beings. Behavioral interventions and their models have largely focused on the individual. ${ }^{71}$ The power of a connected provider-patient relationship to influence patients' behavior should be studied and not underestimated or ignored. Grounded in the Social Cognitive Theory, we have developed a model that includes accountability as a key construct. Although all the constructs that account for this model have been validated, the model itself has not. This modification of the Social Cognitive Theory model will permit both testing the role of accountability in this model and the development and refinement of new interventions to promote better adherence.

\section{Disclosure}

Dr Feldman is a speaker for Taro, a consultant and speaker for Galderma, Abbvie, Celgene, Abbott Labs, Lilly, Janssen, Novartis Pharmaceuticals, and Leo Pharma Inc., has received grants from Galderma, Janssen, Abbott Labs, Abbvie, Celgene, Taro, Sanofi, Novartis Pharmaceuticals, Qurient, Pfizer Inc, and Anacor, is a consultant for Advance Medical, Caremark, Gerson Lehrman Group, Guidepoint Global, Kikaku, Lilly, Merck \& Co Inc, Mylan, Pfizer Inc, Qurient, Sanofi, Sienna, Sun Pharma, Suncare Research, Valeant, and Xenoport, is the founder, Chief Technology Officer, and holds stock in Causa Research, holds stock and is the majority owner in Medical Quality Enhancement Corporation, and receives royalties from UpToDate, Informa, and Xlibris. The other authors report no conflicts of interest in this work.

\section{References}

1. Williams R. Leadership Accountability in a Globalizing World. London, UK: Palgrave Macmillan; 2006.

2. Bernat A, Teller P, Gates A, Delgado N. Structuring the student research experience. ACM SIGCSE Bull. 2000;32(3):17-20.

3. Accountability. In: Merriam-Webster; 2016. Available from: http:// www.merriam-webster.com/dictionary/accountability. Accessed October 15, 2016.

4. Feldman SR, Vrijens B, Gieler U, Piaserico S, Puig L, van de Kerkhof P. Treatment adherence intervention studies in dermatology and guidance on how to support adherence. Am J Clin Dermatol. 2017;18(2):253-271.

5. Yentzer BA, Gosnell AL, Clark AR, et al. A randomized controlled pilot study of strategies to increase adherence in teenagers with acne vulgaris. J Am Acad Dermatol. 2011;64(4):793-795.

6. Feldman SR, Camacho FT, Krejci-Manwaring J, Carroll CL, Balkrishnan R. Adherence to topical therapy increases around the time of office visits. J Am Acad Dermatol. 2007;57(1):81-83.

7. Sagransky MJ, Yentzer BA, Williams LL, Clark AR, Taylor SL, Feldman SR. A randomized controlled pilot study of the effects of an extra office visit on adherence and outcomes in atopic dermatitis. Arch Dermatol. 2010;146(12):1428.

8. Düsing R, Lottermoser K, Mengden T. Compliance with drug therapynew answers to an old question. Nephrol Dial Transplant. 2001;16(7): $1317-1321$.

9. Van Onzenoort HAW, Menger FE, Neef C, et al. Participation in a clinical trial enhances adherence and persistence to treatment: a retrospective cohort study. Hypertension. 2011;58(4):573-578.

10. Glanz K, Bishop DB. The role of behavioral science theory in development and implementation of public health interventions. Annu Rev Public Health. 2010;31(1):399-418.

11. Avery KNL, Donovan JL, Horwood J, Lane JA. Behavior theory for dietary interventions for cancer prevention: a systematic review of utilization and effectiveness in creating behavior change. Cancer Causes Control. 2013;24(3):409-420.

12. Broekhuizen K, Kroeze W, van Poppel MNM, Oenema A, Brug J. A systematic review of randomized controlled trials on the effectiveness of computer-tailored physical activity and dietary behavior promotion programs: an update. Ann Behav Med. 2012;44(2):259-286.

13. Noar SM, Benac CN, Harris MS. Does tailoring matter? Meta-analytic review of tailored print health behavior change interventions. Psychol Bull. 2007;133(4):673-693.

14. Eccles M, Grimshaw J, Walker A, Johnston M, Pitts N. Changing the behavior of healthcare professionals: the use of theory in promoting the uptake of research findings. J Clin Epidemiol. 2005;58(2):107-112.

15. Michie S, Abraham C. Interventions to change health behaviours: evidence-based or evidence-inspired? Psychol Health. 2004;19(1): 29-49.

16. Glanz K, Rimer BK, Lewis FM. Health Behavior and Health Education: Theory, Research, and Practice. San Francisco: Jossey-Bass; 2002.

17. Janz NK, Becker MH. The health belief model: a decade later. Heal Educ Behav. 1984;11(1):1-47.

18. Jackson T. Motivating Sustainable Consumption: A Review of Evidence on Consumer Behaviour and Behavioural Change. Guildford: Centre for Environmental Strategy; 2005.

19. Magrin ME, D'Addario M, Greco A, et al. Social support and adherence to treatment in hypertensive patients: a meta-analysis. Ann Behav Med. 2015;49(3):307-318.

20. McCambridge J, Witton J, Elbourne DR. Systematic review of the Hawthorne effect: new concepts are needed to study research participation effects. J Clin Epidemiol. 2014;67(3):267-277. 
21. Podsadecki TJ, Vrijens BC, Tousset EP, Rode RA, Hanna GJ. "White coat compliance" limits the reliability of therapeutic drug monitoring in HIV-1-infected patients. HIV Clin Trials. 2008;9(4):238-246.

22. Bailey ST. Release Your Brilliance: The 4 Steps to Transforming Your Life and Revealing Your Genius to the World. New York, NY: Harper Collins; 2008.

23. Accountable2You. Internet Accountability and Monitoring; 2014. Available from: https://www.accountable2you.com/. Accessed February 19, 2017.

24. Yentzer BA, Wood AA, Sagransky MJ, et al. An Internet-based survey and improvement of acne treatment outcomes. JAMA Dermatol. 2011; 147(10): 1223 .

25. Dréno B, Thiboutot D, Gollnick H, et al. Large-scale worldwide observational study of adherence with acne therapy. Int $J$ Dermatol. 2010;49(4):448-456.

26. Alinia H, Moradi Tuchayi S, Smith JA, et al. Long-term adherence to topical psoriasis treatment can be abysmal: a 1-year randomized intervention study using objective electronic adherence monitoring. Br J Dermatol. 2017;176(3):759-764.

27. Bass AM, Farhangian ME, Feldman SR. Internet-based adherence interventions for treatment of chronic disorders in adolescents. Adolesc Health Med Ther. 2015;6:91-99.

28. Ryan RM, Deci EL. Self-determination theory and the facilitation of intrinsic motivation, social development, and well-being. Am Psychol. 2000;55(1):68-78.

29. Rogers T, Ternovski J, Yoeli E. Potential follow-up increases private contributions to public goods. Proc Natl Acad Sci US A. 2016;113(19): $5218-5220$.

30. Glanz K, Rimer BK, Viswanath K. Health Behaviour and Health Education. San Francisco: Jossey-Bass; Vol 63; 2008.

31. Andersen RM. Revisiting the behavioral model and access to medical care: does it matter? J Health Soc Behav. 1995;36(1):1-10.

32. Fisher JD, Fisher WA. Changing AIDS-risk behavior. Psychol Bull. 1992;111(3):455-474.

33. Fishbein M, Yzer MC. Using theory to design effective health behavior interventions. Commun Theory. 2003;13(2):164-183.

34. Bandura A. Social Foundations of Thought and Action: A Social Cognitive Theory. New Jersey: Prentice-Hall, Inc; 1986.

35. Ajzen I. From intentions to actions: a theory of planned behavior. In: Action Control. Berlin, Heidelberg, Germany: Springer; 1985:11-39.

36. Ryan RM, Kuhl J, Deci EL. Nature and autonomy: an organizational view of social and neurobiological aspects of self-regulation in behavior and development. Dev Psychopathol. 1997;9(4):701-728.

37. Deci EL, Ryan RM. Cognitive evaluation theory. In: Intrinsic Motivation and Self-Determination in Human Behavior. Boston, MA, USA: Springer; 1985:87-112.

38. Waterman AS. Two conceptions of happiness: contrasts of personal expressiveness (eudaimonia) and hedonic enjoyment. J Pers Soc Psychol. 1993;64(4):678-691.

39. Ryan RM, Frederick C. On energy, personality, and health: subjective vitality as a dynamic reflection of well-being. J Pers. 1997;65(3):529-565.

40. Reis HT, Sheldon KM, Gable SL, Roscoe J, Ryan RM. Daily well-being: the role of autonomy, competence, and relatedness. Pers Soc Psychol Bull. 2000;26(4):419-435.

41. Deci EL, Ryan RM. Toward an organismic integration theory. In: Intrinsic Motivation and Self-Determination in Human Behavior. Boston, MA: Springer; 1985:113-148.

42. Ryan RM, Deci EL. Intrinsic and extrinsic motivations: classic definitions and new directions. Contemp Educ Psychol. 2000;25:54-67.

43. Williams GC, Grow VM, Freedman ZR, Ryan RM, Deci EL. Motivational predictors of weight loss and weight-loss maintenance. $J$ Pers Soc Psychol. 1996;70(1):115-126.

44. Friederichs SA, Oenema A, Bolman C, Lechner L. Long term effects of self-determination theory and motivational interviewing in a web-based physical activity intervention: randomized controlled trial. Int J Behav Nutr Phys Act. 2015;12(1):101.
45. Wood R, Bandura A. Social cognitive theory of organizational management. Acad Manag Rev. 1989;14(3):361.

46. Bandura A. Self-efficacy: toward a unifying theory of behavioral change. Psychol Rev. 1977;84(2):191-215.

47. Tougas ME, Hayden JA, McGrath PJ, Huguet A, Rozario S. A systematic review exploring the social cognitive theory of self-regulation as a framework for chronic health condition interventions. PLoS One. 2015;10(8):e0134977.

48. Stacey FG, James EL, Chapman K, Courneya KS, Lubans DR. A systematic review and meta-analysis of social cognitive theory-based physical activity and/or nutrition behavior change interventions for cancer survivors. J Cancer Surviv. 2015;9(2):305-338.

49. Young MD, Plotnikoff RC, Collins CE, Callister R, Morgan PJ. Social cognitive theory and physical activity: a systematic review and metaanalysis. Obes Rev. 2014;15(12):983-995.

50. Plotnikoff RC, Costigan SA, Karunamuni N, Lubans DR. Social cognitive theories used to explain physical activity behavior in adolescents: a systematic review and meta-analysis. Prev Med. 2013;56(5): 245-253.

51. Viget. Autonomy and Accountability: How Leaders Achieve Miracles With Their Teams; 2016. Available from: https://www.viget.com/ articles/autonomy-and-accountability-how-ceos-achieve-miracles-withtheir-teams. Accessed February 24, 2017.

52. Ramsay R, Ward A, Treasure J, Russell GF. Compulsory treatment in anorexia nervosa. Short-term benefits and long-term mortality. Br J Psychiatry. 1999;175:147-153.

53. Sheehan KA. Compulsory treatment in psychiatry. Curr Opin Psychiatry. 2009;22(6):582-586

54. Deci EL, Cascio WF, Krusell J. Cognitive evaluation theory and some comments on the Calder and Staw critique. J Pers Soc Psychol. 1975;31(1):81-85.

55. Schwarzer R. Skalen Zur Erfassung von Lehrer-Und Sch\{ü\}lermerkmalen [Scales to the determination of teachers' and students' characteristics]: Dokumentation Der Psychometrischen Verfahren Im Rahmen Der Wissenschaftlichen Begleitung Des Modellversuchs Selbstwirksame Schulen. Berlin: R. Schwarzer; 1999. German.

56. Bandura A. Guide for constructing self-efficacy scales. In: Self-Efficacy Beliefs of Adolescents. Greenwich, CT: IAP; 2006:307-337.

57. Cutrona CE, Russell DW. The provisions of social relationships and adaptation to stress. In: Advances in Personal Relationships. Stamford (CT): JAI Press; 1987:37-67.

58. Hamilton M. Rating depressive patients. J Clin Psychiatry. 1980; 41(12 Pt 2):21-24.

59. La Monica EL, Oberst MT, Madea AR, Wolf RM. Development of a patient satisfaction scale. Res Nurs Health. 1986;9(1):43-50.

60. Hall MA, Camacho F, Dugan E, Balkrishnan R. Trust in the medical profession: conceptual and measurement issues. Health Serv Res. 2002;37(5):1419-1439.

61. Thom DH, Wong ST, Guzman D, et al. Physician trust in the patient: development and validation of a new measure. Ann Fam Med.2011;9(2): $148-154$.

62. Nieuwlaat R, Wilczynski N, Navarro T, et al. Interventions for enhancing medication adherence. Cochrane Database Syst Rev. 2014; 11:CD000011.

63. Lam WY, Fresco P. Medication adherence measures: an overview. Biomed Res Int. 2015;2015:1-12.

64. Cramer J, Rosenheck R, Kirk G, Krol W, Krystal J; VA Naltrexone Study Group 425. Medication compliance feedback and monitoring in a clinical trial: predictors and outcomes. Value Health. 2003;6(5): 566-573.

65. Haynes RB, McDonald HP, Garg AX. Helping patients follow prescribed treatment: clinical applications. JAMA. 2002;288(22):2880-2883.

66. Osterberg L, Blaschke T. Adherence to medication. $N$ Engl J Med. 2005;353(5):487-497.

67. Jackevicius CA. Adherence with statin therapy in elderly patients with and without acute coronary syndromes. JAMA. 2002;288(4):462-467. 
68. Hodari KT, Nanton JR, Carroll CL, Feldman SR, Balkrishnan R. Adherence in dermatology: a review of the last 20 years. J Dermatolog Treat. 2006;17(3):136-142.

69. Institute of Medicine (US) Committee on Health and Behavior. Health and Behavior. Washington, DC: National Academies Press; 2001.

70. Mosser G, Sakowski J. Establishing a central structure for supporting guideline implementation. Med Interface. 1996;9(7):136-139.
71. Cutler DM. Behavioral health interventions: what works and why? In: Anderson NB, Bulatao RA, Cohen B, editors. Critical Perspectives on Racial and Ethnic Differences in Health in Late Life. Washington, DC: National Academies Press; 2004:643-667.

72. Servier medical art [homepage on the Internet]. Powerpoint image bank. Servier; 2013 [modified August 8, 2013]. Available from: http://www. servier.com/Powerpoint-image-bank. Accessed July 3, 2017. 


\section{Supplementary material}

Table SI Dominant health behavior models and their constructs

\begin{tabular}{|c|c|c|}
\hline Model & Developed & Key concepts mediating behavior \\
\hline Andersen's behavioral model & Andersen' & $\begin{array}{l}\text { - Societal factors (eg, technology, norms) } \\
\text { - Health services system factors (resources, organization) } \\
\text { - Personal factors (eg, illness level, age, knowledge of disease) }\end{array}$ \\
\hline Health Belief Model & $*$ Rosenstock ${ }^{7,8}$ & $\begin{array}{l}\text { - Perceived susceptibility of condition } \\
\text { - Perceived severity of condition } \\
\text { - Perceived benefits of recommended action } \\
\text { - Perceived barriers of recommended action } \\
\text { - Cues to action (ie, aids that remind individual) } \\
\text { - Self-efficacy }\end{array}$ \\
\hline $\begin{array}{l}\text { Information motivation } \\
\text { behavioral skills model }\end{array}$ & Fisher and Fisher ${ }^{2}$ & $\begin{array}{l}\text { - Information (eg, knowledge of condition) } \\
\text { - Motivation (eg, personal attitudes toward adherence, social support for the } \\
\text { behavior, norm of how others with condition behave) } \\
\text { - Behavior skills (eg, individual has skills and tools available, self-efficacy) }\end{array}$ \\
\hline Integrated Behavior Model & NIMH theorists', 2000s ${ }^{3}$ & $\begin{array}{l}\text { - Attitude toward outcome (ie, belief toward an outcome, evaluation of the outcome) } \\
\text { - Subjective norm (ie, belief of what others think, what experts think) } \\
\text { - Motivation to comply with others } \\
\text { - Self-efficacy } \\
\text { - Knowledge and skills to carry out the behavior } \\
\text { - Importance of behavior } \\
\text { - Environmental constraints } \\
\text { - Habit }\end{array}$ \\
\hline Self-Determination Theory & Ryan and Deci ${ }^{4}$ & $\begin{array}{l}\text { - Cognitive Evaluation Theory (competence, autonomy, and relatedness) } \\
\text { - Organismic Integration Theory (autonomous, controlled) }\end{array}$ \\
\hline Social Cognitive Theory & Bandura $^{5}$ & $\begin{array}{l}\text { - Personal factors } \\
\text { - Environmental factors } \\
\text { - Behavioral factors (reciprocal determinism) }\end{array}$ \\
\hline Theory of Planned Behavior & Fishbein and Ajzen ${ }^{6}$ & $\begin{array}{l}\text { - Attitude toward outcome (ie, belief toward an outcome, evaluation of the outcome) } \\
\text { - Subjective norm (ie, belief of what others think, what experts think) } \\
\text { - Motivation to comply with others } \\
\text { - Self-efficacy }\end{array}$ \\
\hline Theory of Reasoned Action & Fishbein and Ajzen ${ }^{6}$ & $\begin{array}{l}\text { - Attitude toward outcome (ie, belief toward an outcome, evaluation of the outcome) } \\
\text { - Subjective norm (ie, belief of what others think, what experts think) } \\
\text { - Motivation to comply with others }\end{array}$ \\
\hline
\end{tabular}

Note: *Health Belief Model was originally developed by Rosenstock, but another cited reference gives a better overview of the theory.

\section{References}

1. Andersen RM. Revisiting the behavioral model and access to medical care: does it matter? J Health Soc Behav. 1995;36(1):1-10.

2. Fisher JD, Fisher WA. Changing AIDS-risk behavior. Psychol Bull. 1992;111(3):455-474.

3. Fishbein M, Yzer MC. Using theory to design effective health behavior interventions. Commun Theory. 2003;13(2):164-183.

4. Ryan RM, Deci EL. Self-determination theory and the facilitation of intrinsic motivation, social development, and well-being. Am Psychol. 2000;55(1):68-78.

Patient Preference and Adherence

\section{Publish your work in this journal}

Patient Preference and Adherence is an international, peer-reviewed, open access journal that focuses on the growing importance of patient preference and adherence throughout the therapeutic continuum. Patient satisfaction, acceptability, quality of life, compliance, persistence and their role in developing new therapeutic modalities and compounds to optimize
5. Bandura A. Social Foundations of Thought and Action: A Social Cognitive Theory. New Jersey: Prentice-Hall, Inc; 1986.

6. Ajzen I. From intentions to actions: a theory of planned behavior. In: Action Control. Berlin, Heidelberg, Germany: Springer; 1985:11-39.

7. Janz NK, Becker MH. The health belief model: a decade later. Heal Educ Behav. 1984;11(1):1-47.

8. Rosenstock IM. Historical Origins of the Health Belief Model. Heal Educ Behav. 1974;2(4):328-335.

\section{Dovepress}

clinical outcomes for existing disease states are major areas of interest for the journal. This journal has been accepted for indexing on PubMed Central. The manuscript management system is completely online and includes a very quick and fair peer-review system, which is all easy to use. Visit http://www. dovepress.com/testimonials.php to read real quotes from published authors. 